Boise State University

ScholarWorks

Biology Faculty Publications and Presentations

Department of Biological Sciences

9-1-2017

\title{
Natural History Collections: Teaching About Biodiversity Across Time, Space, and Digital Platforms
}

Anna K. Monfils

Central Michigan University

Karen E. Powers

Radford University

Christopher J. Marshall

Oregon State University

Christopher T. Martine

Bucknell University

James F. Smith

Boise State University

See next page for additional authors 
Authors

Anna K. Monfils, Karen E. Powers, Christopher J. Marshall, Christopher T. Martine, James F. Smith, and L. Alan Prather 


\title{
Natural History Collections: Teaching about Biodiversity Across Time, Space, and Digital Platforms
}

\author{
Anna K. Monfils ${ }^{1}$, Karen E. Powers ${ }^{2, *}$, Christopher J. Marshall ${ }^{3}$, \\ Christopher T. Martine ${ }^{4}$, James F. Smith ${ }^{5}$, and L. Alan Prather ${ }^{6}$
}

\begin{abstract}
Natural history collections offer unique physical and virtual opportunities for formal and informal progressive learning. Collections are unique data in that they each represent a biological record at a single place and time that cannot be obtained by any other method. Collections-based experiences lead to an increased understanding of and substantive interaction with the living world. Global biological diversity and changes in that diversity are directly tracked through specimens in collections, regardless of whether changes are ancient or recent. We discuss how collections, specimens, and the data associated with them, can be critical components linking nature and scientific inquiry. Specimens are the basic tools for educating students and interested citizens through direct or virtual contact with the diversity of collections. Such interactions include instruction in a formal classroom setting, volunteering to gather and curate collections, and informal presentations at coffee shops. We emphasize how the recent surge in specimen-based digitization initiatives has resulted in unprecedented access to a wealth of biodiversity information and how this availability vastly expands the reach of natural history collections. The emergence of online databases enables scientists and the public to utilize the specimens and associated data contained in natural history collections to address global, regional, and local issues related to biodiversity in a way that was unachievable a decade ago.
\end{abstract}

\section{Introduction}

Natural history collections (NHCs) house, preserve, catalogue, and archive biological, geological, and anthropological specimens and objects that provide a physical record of biodiversity in the natural world. Study of specimens in NHCs provides access to verifiable data that can be examined and re-examined over time to validate research and provide additional insight into the living world (Page et al. 2015, Prather et al. 2004, Suarez and Tsutsui 2004). Use of specimens in science education is by no means new, and many NHCs maintain educational material specifically for use in formal classes and workshops often related to the diversity of a particular taxonomic sub-discipline (e.g., botany, entomology, herpetology, etc.). In these classes, specimens serve as exemplars of a particular taxon, providing students a hands-on 3-dimensional learning experience that helps them recognize and understand the organisms they encounter in nature.

${ }^{1}$ Central Michigan University, Mount Pleasant, MI 48859. ${ }^{2}$ Biology Department, Box 6931 , Radford University, Radford, VA 24142. ${ }^{3}$ Department of Integrative Biology, Oregon State University, Corvallis, OR 97331. ${ }^{4}$ Department of Biology, Bucknell University, Lewisburg, PA 17837. ${ }^{5}$ Department of Biological Sciences Boise State University, 1910 University Drive, Boise, ID, 83725. ${ }^{6}$ Herbarium and Department of Plant Biology, Michigan State University, East Lansing, MI 48824. *Corresponding author - kpowers4@radford.edu.

Manuscript Editor: Jason Cryan 
NHC specimens, and more importantly, the data associated with each specimen, are being used to educate about biodiversity in general, i.e., the large-scale biological patterns and processes that take place over ecological and evolutionary scales (Chapman 2005, Cook et al. 2014, Powers et al. 2014). This recent focus on specimen data is largely due to the ever-increasing amount of information that is available online (Barkworth and Murrell 2012, Dietrich et al. 2012, Page et al. 2015).

The specimens and objects contained in NHCs represent a specific place and point in time; thus, natural history collections house and curate truly unique resources for studies of biodiversity. These physical specimens can also form a fundamental bridge between student learning experiences in the outdoor classroom and scholarly inquiry in biodiversity-related science (Cook et al. 2014, Powers et al. 2014). Every specimen is a product of active nature exploration by a particular student, scientist, or naturalist and, as such, is a reflection of that quintessential field experience.

Natural history museums and herbaria are research facilities whose collections range broadly in size, geographic coverage, organismal diversity, and staff expertise. They share the common threads of documenting global biodiversity, training the next generation of scientists, and serving the community as epicenters of organismal expertise and education (Suarez and Tsutsui 2004). The specimens and associated data are freely exchanged among institutions of all sizes, allowing for comparative study representing the range of variation across the globe and spanning geological time (Beaman and Cellinese 2012, Graham et al. 2004). Many specimens in collections at academic institutions are a direct product of outdoor learning and research.

In addition to the traditional on-site explorations with actual specimens, technological developments now allow virtual investigations of digitized, databased specimens and associated metadata that have increased the pool of students and citizen scientists who can access what is archived in NHCs. Educators at all levels and in all capacities (formal and informal settings, service learning opportunities, and citizen scientist initiatives) can share what they learn from direct examination of physical, virtual, and digital-specimen data in environments outside of the physical collection. Natural history collections and outdoor-learning experiences thus have the potential to reinforce each other. Collections and the specimens they house provide direct interaction with biodiversity as it changes through time and space, and collections-based experiences naturally lead to an increased understanding and substantive interaction with the living world (Efthim 2006, Kimble 2014, Pickering et al. 2012). When used effectively, museum specimens can engage students in the questions and inquiry of science, provide physical evidence for biological phenomena, and facilitate a hands-on experience with nature that can be personalized, place-based, and immediately relevant.

\section{New Opportunities in Collections-based Research}

Natural history collections are the foundation of an active and vibrant science that continues a rich tradition of scientific exploration. NHCs are the cornerstone of organismal biology and our understanding of evolution and ecology. It is in NHCs 
that many of our most renowned scientists made the observations that initiated their careers and advanced our understanding of the origin, evolution, and maintenance of biodiversity. Charles Darwin, Jane Goodall, Stephen J. Gould, Louis Leakey, Peter Raven, Alfred Russel Wallace, and E.O. Wilson began their research and found their inspiration in NHCs (Desmond and Moore 1991, Green 1986, Lewis 2008, Morell 1995, Shermer 2002, Sullivan and Eaton 2008, Wallace 1905, Wilson 1994). This legacy of inspiration continues as today's scientists turn to NHCs to address emerging societal issues of resource management, climate change, biodiversity loss, invasive species, anthropogenic disturbance, and national security (e.g., Crawford and Hoagland 2009, Francl et al. 2010, Gallagher et al. 2009, Hoffmaster et al. 2002, Huebner 2003, Lavoie 2013, Pauw and Hawkins 2011, Peakall 1974, Primack et al. 2004, Pyke and Ehrlich 2010, Willis et al. 2003).

In recent years, the scientific community has embraced the value of NHC specimens (Lavoie 2013, Pyke and Ehrlich 2010). What started as a grass-roots effort among collection professionals to augment, validate, and preserve our natural heritage has resulted in a community-driven Network Integrated Biocollections Alliance (NIBA) strategic plan for digitizing the close to 1 billion specimens housed in US natural history collections (American Institute of Biological Sciences 2013, NIBA 2010). Additionally, these efforts produced a newly formed and funded initiative through the National Science Foundation (NSF), titled "Advancing Digitization of Biological Collections" (ADBC), and a national Home Uniting Biocollections (HUB) titled "Integrated Digitized Biocollections" (iDigBio), to integrate resources and standardize best practices for over 15 funded multi-institutional NSF thematic collection networks focused around research themes of national importance.

Digitization initiatives are making available unprecedented amounts of verifiable, specimen-based NHC specimen data that is the basis for our understanding of biodiversity and how it has changed and continues to change through time and across geographic space. Specimen-occurrence data, associated metadata, and images from specimens in NHCs are now becoming publicly available in easily accessible digitized formats. Collaborative national and international digitization efforts have centralized the data in common aggregators or portals (e.g., Global Biodiversity Infrastructure [GBIF]), where primary data, once only available to onsite collections-based researchers or by searching through hard-to-obtain published accounts, checklists, and monographs, can now be more efficiently searched and viewed in tandem with other environmental-data sources (e.g., WorldClim - Global Climate Data). Digitization of NHC specimens worldwide expands their accessibility from the regional to the global community. The data and images linked to each biological specimen provide students with a new virtual opportunity to interact with nature. Data from specimens is widely available and provides a rich data source for students to investigate questions about the living world (Cook et al. 2014, Powers et al. 2014).

Physical specimens, combined with online access to specimen-data, afford new opportunities to create both formal and informal progressive learning environments through which students and the public can view and interact with various forms 
of primary and secondary information about biodiversity (Efthim 2006). With the influx of resources for specimen digitization and curation, more students than ever before can participate in collecting, archiving, and cataloging biodiversity. Students without direct access to specimens can now study them in a virtual manner, using a myriad of databases and image repositories. Mirroring the digital library revolution that took place 30 years ago (Candela et al. 2011), the initiatives to put the NHCs on the world-wide web are changing the knowledge base of biodiversity by increasing availability. Access to primary specimen data allows students from both science and non-science disciplines to ask and answer questions that previously would not, or could not, have been asked. In short, digitized data allows anyone to access and pursue their own interests and explore the information in potentially new and exciting ways (McFlannery 2013).

\section{Collecting and Sharing Biodiversity Data in the 21st Century}

\section{Actively cataloging biodiversity}

We are in a time of steep declines in biodiversity, and our welfare depends on conservation of remaining biodiversity and ecosystems (Blaikie and Jeanrenaud 1996). In 2012, the United Nations unveiled an ambitious new global strategy to combat the alarming loss in global biodiversity (United Nations Development Program 2012). Active NHCs provide unique opportunities for research and scholarship (McDade et al. 2011) and play a fundamental role in characterizing global diversity and addressing issues related to biodiversity conservation (Daly et al. 2012, NIBA 2010, Page et al. 2005).

The specimens in NHCs form the basis for how we understand Earth's biota (past and present) and how it has changed over various time scales. Taxonomists, whose research encompasses the description and classification of biodiversity, base their work on the study of living, formerly living, or fossilized biological materials. Researchers have been collecting specimens for hundreds of years, and fossils extend our records of the Earth's biota an astounding 3.4 billion years (Wacey et al. 2011). Each of the almost 3 billion specimens archived in NHCs constitutes an empirical, verifiable physical record (scientific evidence) of an organism at a particular place and time, thus allowing successive taxonomists to re-evaluate the species as a whole and in light of new discoveries, techniques, or data (e.g., genomes, behavior, new species, etc.).

Collectively, museum specimens document how species are distributed, how biodiversity has changed, and what factors drive diversification and extinction in space and time (Page et al. 2005). Although it surprises many people, the vast majority of our planet's biodiversity consists of small, rarely encountered and poorly understood species (Albano et al. 2011, Rocha et al. 2014). For many of these species, virtually everything we know about them emanates from a small number of museum specimens and the labels or field notes associated with them (Lim et al. 2011). For widespread species, museum specimens can provide an efficient means to sample across a large geographic region (Beck and Kitching 2007). In light of ongoing concern about habitat destruction, climate change, 
non-native invasive species, and introduced pathogens (Loarie et al. 2008), museum specimens have become increasingly useful for studying common species to identify clues to understanding species decline (Grixti et al. 2009). Thus, institutions that provide stewardship of NHCs and specimens are not only generating the primary means to study and reverse biodiversity loss, but are simultaneously insuring that scientists will have examples to study even if the worst-case scenario-species extinction-occurs.

\section{Educational Opportunities in the 21st Century: Formal and Informal Learning}

The benefits of outdoor learning in combination with use of NHCs are synergistic. Outdoor classrooms expose students to learning in a setting with benefits that cannot be realized indoors. Research has established that exposure to nature can improve cognitive functioning (Berman et al. 2008), boost creative reasoning (Atchley et al. 2012), and improve attention spans (Lee et al. 2015). These benefits can lead to engagement with learning and stimulate interest in scientific inquiry. NHC specimens and associated data can both provide an avenue to explore questions posed or generated in the outdoor classroom and, in turn, refine those questions or stimulate new lines of inquiry. Thus, NHCs can help users maximize the demonstrated benefits of exposure to nature.

\section{Student scientists}

Today's young people have been identified as having a "nature deficit" (Louv 2008, Tewksbury et al. 2014), and NHCs can serve a vital role in introducing students to natural systems and critical global issues related to them. Access to collections plays a pivotal role in inspiring thoughtful, hypothesis-driven ideas related to biodiversity and environmental challenges, as well as the associated emerging socioeconomic and public health challenges of the 21 st century. Such inspiration has significant potential to engage younger generations with the natural world.

Academic departments with access to in-house NHC specimens are able to offer a breadth of curricular options enriched by the presence of real organisms. The characteristics that define Earth's biodiversity and underlie centuries of taxonomic organization are best learned when observed on the specimens themselves. Digitization initiatives have built on the value of the specimens by providing a data context. This immense, ever-expanding dataset associated with NHC specimens represents biological snapshots through space and time. Massive specimen-based datasets are easily mined for learning activities that encourage the development of transferable skills including the abilities to acquire, evaluate and analyze information from multiple sources; synthesize ideas from across disciplines; choose and utilize appropriate methods of quantification; and use or develop new technologies related to data storage and management. Whether course-related, or as an outcome of an independent research project, student engagement develops a vested interest in the learning process.

The very nature of collections as primary sources of data allows student researchers to participate in the scientific process from beginning to end, including 
the conversion of primary observations into scientific hypotheses. Student involvement in collections gives them the capacity to interact directly with researchers who are working with the collection as well as many partnering agencies and institutions. Outreach opportunities abound when students are engaged in field-based and/ or collections research. These activities can be transformative for the next generation of students pursuing careers as scientists.

A growing network of museum scientists, collections specialists, field biologists, undergraduate educators, and artists are investigating, developing, and implementing novel ways of incorporating the extensive archives and new cyberinfrastructure of natural history museums into undergraduate education. Funding from NSF enabled this network to develop the Advancing Integration of Museums in Undergraduate Programs (AIM-UP!). AIM-UP! was initiated as a research coordination network in undergraduate biological education (http://aimup.unm.edu). Membership in this consortium continues to grow as more and more educators explore and share resources that utilize the tremendous potential of our vast natural history collections and associated databases to contribute to teaching and research experiences in biology (Cook et al. 2014).

\section{Citizen scientists}

Incorporating a citizen science approach can facilitate advances in science, while at the same time engaging the public in research and related management or policy issues and also educating them in scientific methods and subject matter. In addition to curatorial staff and student workers, some NHCs maintain and support a diverse and energetic community of citizen scientists. These individuals may simply be interested in a particular focus group within the museum; however, they often have advanced degrees themselves and/or years of personal experience associated with the local biodiversity. Some of the citizen scientists are associated with local or regional conservation groups (e.g., master naturalists), while others are former student scientists or simply interested, creative individuals (Bonney et al. 2009).

Citizen scientists devote thousands of hours of volunteer labor to NHCs in the form of specimen collecting, deposition, preparation, and identification. As such, they often have a long-term vested interest in those specimens and the institutions housing them (Bonney et al. 2009). Their outreach activities (e.g., science cafes, outdoor lecture series, etc.) make them an invaluable addition to any stand-alone NHC or university-supported NHC.

Citizen scientists are active participants in gathering data and promoting research. The Notes from Nature (NfN) transcription project (http://www.notesfromnature. org/) works with citizen scientists to transcribe records from the world's biological collections (Hill et al. 2012). The NfN project facilitates online participation of citizen scientists in creating, editing, and enhancing the growing digital biodiversity dataset, and gives individual citizens the opportunity to make scientifically important contributions to biodiversity science. This effort has expanded to a global Worldwide Engagement for Digitizing Biocollections (WeDigBio) annual 
transcription event where thousands of transcriptions are performed in a bioblitz format that occur simultaneously in collections all over the world (WeDigBio.org). Along with introducing hundreds of participants to collections and collection-based data, tens of thousands of specimens can get transcribed in a single 4-d period.

\section{Scientific literacy}

We need an engaged, scientifically literate society if we can ever hope to address the emerging societal concerns over issues like climate change, reduced resources, and emerging diseases (Lavoie 2013, McFadden et al. 2007, Tewksbury et al. 2014). Citizens with greater scientific literacy can more effectively follow scientific advancements, discriminate between facts and fallacy, and make informed decisions that impact their daily lives. Citizens who understand the scientific process can better analyze the validity of information and more meaningfully engage in the political process (Maienschein 1999).

Natural history collections have a long and rich history of engaging the public in science education. The values gained by the local community through the use of NHCs serves as a direct return on the investment the public has placed in these institutions. People of all ages enjoy visiting museums and learning about the natural world in these informal settings. In addition to public exhibits, NHC staff are embracing new educational opportunities by presenting public programs that bring information about biodiversity science to venues outside the museum, including nature centers, urban landscapes, and even informal science cafe gatherings at coffee shops. Innovative projects like The Brain Scoop videos generated at the Field Museum, Chicago, IL, make use of emerging resources to provide engaging and informative opportunities to learn about science and thereby enhance the general level of scientific literacy in society.

\section{Conclusion}

Collections provide opportunities for direct observation of known biodiversity and how it changes through time and space. Field- and collections-based experiences naturally lead to an increased understanding and substantive interaction with the living world. The integration of specimen-based data from historical NHC databases combined with field-based, hands-on inventory and exploration can make the science of taxonomy more accessible through novel modes of engagement, inspiring new communities of students and the public to become stewards, natural historians, and scientists. Examination of archived collections translates directly into an increased appreciation of the natural world and encourages continued exploration of and appreciation for global diversity.

\section{Acknowledgments}

We thank the many colleagues that participated in the 7 workshops organized by CollectionsWeb Research Coordination Network: Building a National Community of Natural History Collections and funded by the National Science Foundation (DBI-0639214). Many of the ideas discussed herein grew out of discussions from these workshops, especially the 
"New Approaches to Specimen-based Education" workshop held on October 28 and 29, 2011 at Radford University's Selu Conservancy, Radford, Virginia, United States.

\section{Literature Cited}

Albano, P.G., B. Sabelli, and P. Bouchet. 2011. The challenge of small and rare species in marine-biodiversity surveys: Microgastropod diversity in a complex tropical coastal environment. Biodiversity and Conservation 20:3223-3237.

American Institute of Biological Sciences. 2013. Implementation plan for the Network Integrated Biocollections alliance. Reston, VA. 28 pp. Available on-line at: http://www.aibs. org/public-policy/NIBA_Implementation_Plan.pdf. Accessed 14 August 2015.

Atchley, R.A., D.L. Strayer, and P. Atchley. 2012. Creativity in the wild: Improving creative reasoning through immersion in natural settings PloS One 7:e51474.

Barkworth, M.E., and Z.E. Murrell. 2012. The US Virtual Herbarium: Working with individual herbaria to build a national resource. ZooKeys 209:55-73.

Beaman, R.S., and N. Cellinese. 2012. Mass digitization of scientific collections: New opportunities to transform the use of biological collections and underwrite biodiversity science. ZooKeys 209:7-17.

Beck, J., and I.J. Kitching. 2007. Estimating regional species richness of tropical insects from museum data: A comparison of geography-based and sample-based methods. Journal of Applied Ecology 44:672-681.

Berman, M.G., J. Jonides, and S. Kaplan. 2008. The cognitive benefits of interacting with nature. Psychological Science 19(12):1207-1212.

Blaikie, P., and S. Jeanrenaud. 1996. Biodiversity and human welfare. UNRISD Discussion Paper No. 72. United Nations Research Institute for Social Development, Geneva, Switzerland. 81 pp.A vailable online at http://www.unrisd.org/80256B3C005BCCF9/ (httpAuxPages)/ACA8333A4CB1D7F980256B67005B68F5/\$file/dp72.pdf.

Bonney, R., C.B. Cooper, J. Dickinson, S. Kelling, T. Phillips, K.V. Rosenberg, and J. Shirk. 2009. Citizen science: A developing tool for expanding science knowledge and scientific literacy. Bioscience 59:977-984.

Candela, L., D. Castelli, and P. Pagano. 2011. History, evolution, and impact of digital libraries. Pp. 1-30, In I. Iglezakis, T. Synodinou, and S. Kapidakis (Eds.). E-publishing and Digital Libraries: Legal and Organizational Issues. IGI Global, Hershey, PA. 552 pp.

Chapman, A.D. 2005. Uses of primary species-occurrence data, version 1.0. Report for the Global Biodiversity Information Facility, Copenhagen, Denmark. 106 pp.

Cook, J.A, S.V. Edwards, E.A. Lacey, R.P. Guralnick, P.S. Soltis, D.E. Soltis, C.K. Welch, K.C. Bell, K.E. Galbreath, C. Himes, J.M. Allen, T.A. Heath, A.C. Carnaval, K.L. Cooper, M. Liu, J. Hanken, and S. Ickert-Bond. 2014. Natural history collections as emerging resources for innovative education. Bioscience 64(8):725-734.

Crawford, P.H.C., and B.W. Hoagland. 2009. Can herbarium records be used to map alienspecies invasion and native-species expansion over the past 100 years? Journal of Biogeography 36(4):651-661.

Daly, M., P.S. Herendeen, R.P. Guralnick, M.W. Westneat, and L. McDade. 2012. Systematics agenda 2020: The mission evolves. Systematic Biology 61(4):549-552.

Dietrich, C., J. Hart, D. Raila, U. Ravaioli, N. Sobh, O. Sobh, and C. Taylor. 2012. InvertNet: A new paradigm for digital access to invertebrate collections. ZooKeys 209:165-181.

Desmond, A., and J. Moore. 1991. Darwin. Penguin Group,London, UK. 864 pp.

Efthim, R. 2006. The naturalist center: Proof that museums can do more to maximize the learning potential of their collections. Museum Management and Curatorship 21(1):58-66. 
Francl, K.E., K. Hayhoe, M.E. Saunders, and E.P. Maurer. 2010. Ecosystem adaptation to climate change: Small-mammal migration pathways in the Great Lakes states. Journal of Great Lakes Research. 2009 Special Issue: An Integrated Assessment of Climate Change Impacts and Mitigation for Chicago and the Midwest 36:86-93.

Gallagher, R.V., L. Hughes, and M.R. Leishman. 2009. Phenological trends among Australian alpine species: Using herbarium records to identify climate-change indicators. Australian Journal of Botany 57(1):1-9.

Graham, C.H., S. Ferrier, F. Huettman, C. Moritz, and A.T. Peterson. 2004. New developments in museum-based informatics and applications in biodiversity analysis. Trends in Ecology and Evolution 19(9):497-503.

Green, M. 1986. Stephen Jay Gould: Driven by a hunger to learn and to write. People 25(2 June):109-114.

Grixti, J.C., L.T. Wonga, S.A. Cameron, and C. Favret. 2009. Decline of bumble bees (Bombus) in the North American Midwest. Biological Conservation 142:75-84.

Hill, A., R. Guralnick, A. Smith, A. Sallans, R. Gillespie, M. Denslow, J. Gross, Z. Murrell, T. Conyers, P. Oboyski, J. Ball, A. Thomer, R. Prys-Jones, J. de Torre, P. Kociolek, and L. Fortson. 2012. The notes from nature tool for unlocking biodiversity records from museum records through citizen science. Zookeys 209:219-233.

Hoffmaster, A.R., CC. Fitzgerald, E. Ribot, L.W. Mayer, and T. Popovic. 2002. Molecular subtyping of Bacillus anthracis and the 2001 bioterrorism-associated anthrax outbreak, United States. Emerging Infectious Diseases 8:1111-1116.

Huebner, C.D. 2003. Vulnerability of oak-dominated forests in West Virginia to invasive exotic plants: Temporal and spatial patterns of nine exotic species using herbarium records and land-classification data. Castanea 68(1):1-14.

Kimble, G. 2014. Children learning about biodiversity at an environment centre, a museum, and at live-animal shows. Studies in Education Evaluation 41:48-57.

Lavoie, C. 2013. Biological collections in an ever-changing world: Herbaria as tools for biogeographical and environmental studies. Perspectives in Plant Ecology, Evolution, and Systematics 15:68-76.

Lee, K.E., K.J.H. Williams, L.D. Sargent, N.S.G. Williams, and K.A. Johnson. 2015. 40-second green-roof views sustain attention: The role of micro-breaks in attention restoration. Journal of Environmental Psychology 42:182-189.

Lewis, R. 2008. A career at the museum. Nature 451:218-219.

Lim, G.S, M. Balke, and R. Meier. 2011. Determining species boundaries in a world full of rarity: Singletons, species delimitation methods. Systematic Biology 61 (2011):165-169.

Loarie, S.R., B.E. Carter, K. Hayhoe, S. McMahon, R. Moe, C.A. Knight, and D.D. Ackerly. 2008. Climate change and the future of California's endemic flora. PLoS ONE 3(6):e2502.

Louv, R. 2008. Last Child in the Woods: Saving Our Children from Nature-Deficit Disorder. Algonquin Books, Chapel Hill, NC. 416 pp.

Maienschein, J. 1999. Commentary: To the future-argument for scientific literacy. Science Communication September:101-113.

McDade, L.A., D.R. Maddison, R. Guralnick, H.A. Piowawar, M.A. Jameson, K.M. Helgen, P.S. Herendeen, A. Hill, and M.L. Vis. 2011. Biology needs a modern assessment system for professional productivity. BioScience 61(6):619-625.

McFadden, B.J., B.A. Dunckel, S. Ellis, L.D. Dierking, L. Abraham-Silver, J. Kisiel, and J. Koke. 2007. Natural history museum visitors' understanding of evolution. BioScience 57(10):8755-882. 
McFlannery, M.C. 2013. Plant collections: Using digital herbaria in biology teaching. Bioscene: Journal of College Biology Teaching 39:3-9.

Morell, V. 1995. Ancestral Passions: The Leakey Family and the Quest for Human Beginnings. Simon and Schuster, New York, NY. 640 pp.

Network Integrated Biocollections Alliance (NIBA). 2010. A strategic plan for establishing a Network Integrated Biocollections Alliance. Available online at https://digbiocol.files. wordpress.com/2010/08/niba_brochure.pdf. Accessed 12 August 2015.

Page L.M., H.L. Bart Jr., R. Beaman, L. Bohs, L.T. Deck, V.A. Funk, D. Lipscomb, M.A. Mares, L.A. Prather, J. Stevenson, Q.D. Wheeler, J.B. Woolley, and D.W. Stevenson, 2005. LINNE: Legacy Infrastructure Network for Natural Environments. Illinois Natural History Survey Publication. Available online at http://www.flmnh.ufl.edu/linne/collections.htm.Accessed 4 June 2013.

Page, L.M., B.J. McFadden, J.A. Fortes, P.S. Soltis, and G. Riccardi. 2015. Digitization of biodiversity collections reveals biggest data on biodiversity. BioScience 65:841-842.

Pauw, A., and J.A. Hawkins. 2011. Reconstruction of historical pollination rates reveals linked declines of pollinators and plants. Oikos 120(3):344-349.

Peakall, D.T. 1974. DDE: Its presence in peregrine eggs in 1948. Science 183:673.

Pickering, J., L. Fawcett, and L. Munstermann. 2012. An alternative approach: Teaching evolution in a natural history museum through the topic of vector-borne disease. Museums and Evolution 5:62-67.

Powers, K.E., L.A. Prather, J. Cook, J. Woolley, H. Bart, A. Monfils, and P. Sierwald. 2014. Revolutionizing the use of natural history collections in education. Science Education Review 13(2):24-33.

Prather, L.A., O. Alvarez-Fuentes, M.H. Mayfield, C.J. Ferguson. 2004. Implications of the decline in plant collecting for systematic and floristic research. Systematic Botany 29(1):216-220.

Primack, D., C. Imbres, R.B. Primack, A.J. Miller-Rushing, and P. Del Tredici. 2004. Herbarium specimens demonstrate earlier flowering times in response to warming in Boston. American Journal of Botany 91:1260-1264.

Pyke, G.H., and P.R. Ehrlich. 2010. Biological collections and ecological/environmental research: A review, some observations, and a look to the future. Biological Reviews $85: 247-266$.

Rocha, L.A. et al. 2014. Specimen collection: An essential tool. Science 344:814-815.

Shermer, M. 2002. In Darwin's Shadow: The Life and Science of Alfred Russel Wallace-A Biographical Study on the Psychology of History. Oxford University Press, Inc., Altadena, CA. 444 pp.

Suarez, A.V., and N.D. Tsutsui. 2004. The value of museum collections for research and society. BioScience 54(1):66-74.

Sullivan, R., and J. Eaton. 2008. Peter Raven's Botanical Roots come from S.F. SFGate. com. San Francisco Chronicle, 28 August 2008. Available online at http://www.sfgate. com/homeandgarden/article/Peter-Raven-s-botanical-roots-come-from-S-F-3272448. php\#ixzz2VHBTGVRW. Accessed 4 June 2013.

Tewksbury, J J., J.G.T. Anderson, J.D. Bakker, T.J. Billo, P.W. Dunwiddie, M.J. Groom, S.E. Hampton, S.G. Herman, D.J. Levey, N.J. Machnicki, C.M. del Rio, M.E. Power, K. Rowell, A.K. Salomon, L. Stacey, S.C. Trombulak, and T.A. Wheeler. 2014. Natural history's place in science and society. BioScience 64(4):300-310. 
United Nations Development Program. 2012. The future we want: Biodiversity and ecosystems - driving sustainable development. Biodiversity and ecosystems global framework 2012-2020. Available online at http://www.undp.org/content/dam/undp/library/Environment $\% 20$ and $\% 20$ Energy/biodiversity/UNDP-Biodiversity-and-Ecosystems-GlobalFramework-2012-2020.pdf. Accessed 4 June 2013.

Wacey D., M.R. Kilburn, M. Saunders, J. Cliff, and M.D. Brasier. 2011. Microfossils of sulphur-metabolizing cells in 3.4-billion-year-old rocks of Western Australia. Nature Geoscience 4(10):698-702. Available online at http://www.nature.com/ngeo/journal/v4/ n10/full/ngeo1238.html. Accessed 4 June 2013.

Wallace, A.R. 1905. My life: A Record of Events and Opinions. Chapman and Hall, Ltd., London, UK. 408 pp.

Willis, F., J. Moat, and A. Paton. 2003. Defining a role for herbarium data in Red List assessments: A case study of Plectranthus from eastern and southern tropical Africa. Biodiversity and Conservation 12(7):1537-1552.

Wilson, E.O. 1994. Naturalist. Shearwater Books/Island Press, Washington, DC. 416 pp. 